\title{
Requirements for Application of the STEM Approach as Perceived by Science, Math and Computer Teachers and their Attitudes towards it
}

\author{
Mohareb Ali Alsmadi ${ }^{1 *}$ \\ ${ }^{1}$ Al-Balqa Applied University, Salt, JORDAN
}

Received 9 April 2020 - Accepted 27 June 2020

\begin{abstract}
This research aimed to investigate the requirements of the application of the STEM approach in teaching science and mathematics and the teachers' attitudes towards it. The study used descriptive approach. The study sample consisted of (159) male and female teachers chosen by the random stratified sample method from the study community represented by all science, mathematics and computer teachers in Ajloun Governorate in the academic year 2019/2020. The scale of requirements for applying the STEM approach and teachers' attitudes towards it was developed; the validity and reliability of the study instrument were verified by appropriate statistical methods. Statistical processing was done using arithmetic means, and the analysis of multiple variance analysis. The results showed that the teachers 'assessments of the requirements of the STEM approach are all high and above the hypothetical average (75\%). "Changing the teaching methods" dimension came in the first place with an arithmetic mean (30,29), followed by the dimension of "changing the learning goals" with an arithmetic mean (30.15). The third place was for "changing the vision and skills of teachers" dimension with an arithmetic mean (30.13), and the last place was for the domain of "changing the classroom environment" with an arithmetic mean (22.37). It showed that teachers' attitudes toward STEM teaching are positive and high. And there were no statistically significant differences at the level $(0.05)$ in the male and female teachers' assessments of the requirements of STEM application and their attitudes towards it. On the other hand, there are statistically significant differences in their estimates according to the phase variable and in favor of the elementary stage. There were statistically significant differences according to the variable of specialization and for the benefit of science and mathematics teachers compared to Computer ones. And in light of the results, the study presented a set of recommendations.
\end{abstract}

Keywords: attitudes, integrative approach, STEM approach, teaching mathematics, science and computer

\section{INTRODUCTION}

Jordan, like other developing- world countries, seeks to improve educational opportunities for its students to enable them to face major challenges in the educational and economic fields. With integrated knowledge and science, learners can get to know the world around them correctly, and this knowledge allows them to take advantage of the available capabilities to facilitate their lives, making them more prosperous, and developing their societies. This requires educational systems to keep pace with modern trends in curricula and teaching strategies that allow learners to participate effectively in the production and use of knowledge. Among the most prominent trends that seek to enable learners to contribute to scientific and technological development is STEM education which contributes to transforming learners from merely recipients of knowledge and technology into producers of them, providing them with productive skills such as creative thinking, critical thinking, and creative solution to problems in real contexts. As well, it reduces unemployment problems among graduates (Bybee, 2013; NRC, 2011; Seyranian et al., 2018; Warsi, 2019). 


\section{Contribution to the literature}

- The present study provides a list of the requirements for the application the STEM approach in teaching mathematics, science and computer. Thus, it facilitates the implementation of the STEM Approach by teachers and curriculum planners in reality.

- This study provides the perceptions of teacher of multiple disciplines (mathematics, science, and computer) about teaching STEM. Besides, it highlights their views of the contextual factors and how to implement STEM in order to achieve the optimal impact on students' learning and to teach them certain personal characteristics.

- The literature review presents three requirements for STEM education which are changing objectives, changing teachers 'perceptions, and changing teaching methods. However, the requirements of the physical classroom environment that was discussed in this study should be part of STEM Education.

STEM trend appeared in the United States of America aiming at the development of education to solve various issues in the labor force as facing a decrease in the number of students who were enrolled in professional and engineering study programs (NRC, 2012). STEM also came as a response to improve the competitiveness of the United States and provide employment opportunities for the next generation, especially those who are from low-income groups (Eisenhart, Weis, Allen, Cipollone, Stich, \& Dominguez, 2015). It contributes to building individuals with leadership qualities, the ability to manage the world and direct it towards creativity and innovation, and enables them to face many contemporary local and international challenges (Bybee, 2013). It helps schools support school curricula and enrich science and mathematics lessons by providing opportunities, for teachers, to use activities that support student learning and participation in a dynamic learning environment (Popovic \& Lederman, 2015). This may be because teaching procedures following the STEM approach require achieving integration between aspects of knowledge and practices of science and applied mathematics, and the development of higher-order patterns and training in engineering design, helping learners develop their scientific skills in a way that enables them to understand and perceive different sciences in an integrative and enjoyable manner (Gonzalez \& Kuenzi, 2012, p. 9).

STEM is based on the principles of the structural theory and the integrative approach that rely on the idea that effective learning takes place as a result of the interaction between learners and sensory experience in the world or the surrounding environment, and through this interaction, each learner builds cognitive structures that constitute their understanding of the situations and concepts with which they interact (Berlin \& Kyungpook, 2005). And this is accomplished by establishing links between these concepts, and that these links are formed in the brains of learners in an integrated manner. And if there is any deficiency in the related concepts, the mind will try to adjust them, integrally correcting and linking to previous experiences (Furner, Doan-Holbein, \& Scullion-Jackson, 2000), which make teaching following the STEM approach easier for students to make real meaningful links between knowledge and skills among the STEM topics.

The current study is based on the research framework of STEM integration requirements so that teachers act as planners and facilitators to provide integrated experiences and educational opportunities to learners so that they enrich their deep understanding of the academic content in STEM disciplines (EL-Deghaidy, Mansour, Alzaghibi, \& Alhammad, 2017). Hence the teachers need guidance and awareness of the requirements of applying STEM so that they are ready for such requirements. And part of their willingness is to study the views of teachers in STEM education and how aware they are of the requirements of applying this trend and can be summarized into three general requirements as follows: (A) changing the vision and attitudes of teachers towards teaching science and mathematics so that classroom activities are commensurate with what happens in everyday life, and this requires teachers who focus on integrated experience and focus on meaning rather than knowledge, achieving trust and not fear (Alqadhi \& Rabia, 2018). (B) Changing the methods of teaching science and mathematics to transform learners from mere recipients of knowledge to unique producers of knowledge, and focusing on immersing in scientific knowledge, practicing science and research, investigation, creative problem solving, and scientific thinking. STEM curriculum design requires an emphasis on experience Integrated, practical application, and strategies for developing logical and critical thinking skills, creative thinking, research and investigation skills, and immersing in the question and using alternative assessment methods. (C) Changing vision and education goals so that they seek to achieve a deeper understanding of science and mathematics and their technological and functional applications (Stephanie, 2008, p. 9-11).

Also, the researcher believes that the physical environment of the classroom or the school should be changed so that it is supported by modern technical and technological devices and instruments. Besides, the science lab must be available for mathematics lessons, 
and that it should be enriched with the appropriate equipment and instruments to put mathematical, scientific and engineering knowledge into practice that is contextually similar to the real world.

One of the studies that focused on investigating the requirements of STEM implementation is ( $\mathrm{O}^{\prime}$ Connell, Keys, \& Storksdieck, 2017) study that examined the challenges facing STEM centers, and what are the requirements for activating these centers to create opportunities for partnerships, cooperation, and improving communication within and outside the community of STEM teaching and learning. The study found that investments in infrastructure and programming by the state are among the most prominent requirements of STEM, which have a fundamental role in establishing local STEM centers, besides; STEM Hubs report a variety of ideas to promote further success for STEM centers. The results also showed that employees and primary partners have high satisfaction with the structure and work of the regional states, where most of the concerns are mainly focused on continuous funding and providing sufficient staff.

The Al-bez (2016) study tackled the requirements of applying the STEM approach that must be met in science books, and the study identified 6 main requirements for applying the STEM approach: developing 21st-century skills, incorporating science practices, focusing on integrated concepts, achieving integration among STEM domains, and connecting engineering practices to the economic dimension. The results also showed that the inclusion degree of the former requirements was approximate and at low rates.

The scientific interest in STEM and the applied requirements of science and mathematics curricula led many researchers to study the beliefs and attitudes of teachers about it. Studies have shown that teachers support the idea of integration between science, mathematics, engineering, and technology, or the integration of some of these topics, but they do not know how to achieve this integration (Berlin \& White, 2011). And since teachers have the motivation to teach STEM, as a facilitating process of activism, in schools, they must have positive attitudes about STEM education, and be thinking about STEM (Edward, 2015). Also, teachers' having negative perceptions about STEM hinders their teaching it (EL-Deghaidy, Mansour, Alzaghibi, \& Alhammad, 2017).

Al-Enezi and Algebr (2017) believe that knowing teachers 'perceptions towards STEM is the first step to planning and developing programs in this field, whether it is at the level of teachers' perceptions, or perceptions about the effectiveness of their teaching STEM. Teachers 'perceptions have a strong impact on their adoption of modern curricula and teaching strategies, therefore studying these perceptions works to provide planners of teacher preparation and qualification programs with what must be focused on in these programs so that they achieve modern trends in teaching (Tarman, 2012). The views of teachers and their activation of the STEM approach are affected by their attitudes, experiences, competencies, and self-efficacy (EL-Deghaidy, Mansour, Alzaghibi, \& Alhammad, 2017).

Many studies have dealt with teachers' perceptions and attitudes towards teaching following the STEM approach, including the study of Al-Otaibi (2018) that examined the perceptions of male and female science teachers towards STEM education in Saudi Arabia, concluding that the attitudes of science teachers towards the approach of STEM has been high. There are statistically significant differences at the level (0.01) in the attitudes of teachers according to the gender variable that went for the benefit of the female teachers compared to the male ones. And there are statistically significant differences in their attitudes according to the variable of the study stage and in favor of the elementary stage. Algebr and Al-Enezi (2017) also conducted a study that aimed at studying the perceptions of science teachers in Medina in Saudi Arabia about the STEM curriculum, and the study found that there are high attitudes among teachers towards STEM, and the results revealed that there are statistically significant differences in their perceptions according to the variable of the study stage and were for the benefit of the elementary school teachers. (EL-Deghaidy, Mansour, Alzaghibi, \& Alhammad, 2017) conducted a study that was concerned with exposing the science teachers' beliefs regarding STEM teaching and its interdisciplinary nature. It also sought to define teachers' views on the contextual factors that facilitate and hinder such education in their schools.

The results revealed the teachers 'concerns regarding their less preparation to activate science, technology, engineering, and mathematics practices, indicating that engineering is the least specialization that is combined with science. Kelly and Knowles (2016) also conducted a study aimed at knowing the motivations of teachers to improve education using the STEM approach, and the study concluded that teaching following STEM provides the rationale for teaching the interconnections between science, mathematics, engineering, and technology. The process of integrating science, technology, engineering, and mathematics into complex original contexts, such as global challenges, requires a new generation of STEM experts. And those teachers are striving to establish links across STEM disciplines. Bruce-Davis, Gubbins, Gilson, Villanueva, Foreman, and Rubenstein (2014) also conducted a study aimed at revealing perceptions of high school principals, teachers, and students about STEM. The results showed three topics from data analysis: (a) a mutual vision of a challenging and attractive learning environment, (b) focus on applying educational strategies, curricula, and practices to realworld problems, (c) an assessment of the academic level and emotional support in a challenging learning 
environment. Thus, interested educators may discover strategies and practices to support their tasks.

\section{Commenting on Previous Studies}

We conclude from reviewing previous studies that the current study agreed with them regarding the study of teachers' attitudes towards STEM teaching. But what distinguishes the current study is its interest in studying the requirements of applying STEM teaching in government schools and investigating the teachers' attitudes of all subjects related to STEM teaching disciplines in Jordan: teachers of mathematics, science and computer (educational technology). Unlikely, previous studies were limited to one specialty for teachers such as science or mathematics. Moreover, the study is distinguished by studying the requirements of applying the STEM approach in schools, which are divided into four domains: requirements related to changing learning goals, requirements related to changing' vision, requirements related to teaching methods, and requirements related to the classroom environment.

\section{Study Question}

The general objectives of applying the STEM approach are summarized by improving the interest of learners of both genders in university- education programs in scientific and professional specializations to raise the individual's share of income, facing the problem of unemployment and advancing the national economy by allowing individuals to work to manage projects in the future, especially projects related to STEM specializations (NRC, 2011). Therefore, conducting research about the requirements of implementing STEM in Jordanian schools increases the opportunities for application, which may contribute to solving the economic and educational challenges facing a poor country such as Jordan. Why not and the public debt of Jordan in 2019 reached 29621.7 million dinars or 95.3\% of GDP, recalculated total for 2019 (Ministry of Finance, 2019, p. 7).

The unemployment rate among Jordanian youth reached 19\%, and this may be related directly or indirectly to the level of science and mathematics education which suffers from many problems and a clear deficiency reflected in the results of students in international science and mathematics tests (TIMSS), where eighth-grade students got in 2015 session on 426 points in science subject, and 386 points in mathematics subject. and all of them are below the global average, and with a decline of 20,23 points respectively compared to the 2011 session (TIMSS, 2015). This urgently requires STEM education in Jordan. This may be due to the atmosphere of teaching science, mathematics, engineering, and technology in Jordan, which is based on the separate approach, focusing on the momentum of cognitive content regardless of the reality of this information and its link to the challenges of the current era. The researcher noted that there is a case of the dominion of traditional methods in teaching science and mathematics and their inability to develop different thinking skills, which negatively affects the ability of learners to participate in generating knowledge to face the challenges posed by scientific and technological progress. Accordingly, a need has emerged to conduct a study looking at the requirements of applying STEM approach as one of the entrances to the design and implementation of science and mathematics curricula.

In light of the lack of studies that examined the requirements of applying the STEM approach and teachers' attitudes towards it locally and in the Arab world - within the limits of the researcher's knowledge the study problem emerged to answer the following questions:

1. What are the needed requirements for applying the STEM approach to teaching in Jordan from science, mathematics and computer teachers' points of view?

2. What are the attitudes of science, mathematics and computer teachers toward a STEM approach?

3. Do the mathematics, science, and computer teachers 'estimates about requirements of the STEM approach and their attitudes toward it differ according to the (gender, specialization, and grade level) variables?

\section{Study Importance}

The importance of the study appears in the theoretical framework presented about the importance of STEM education, its requirements, skills, and characteristics so that it provides educational literature for researchers and those interested in the field of STEM education. It also reveals the requirements for implementing STEM in Jordan, and the attitudes of teachers on STEM teaching at various levels of study and from the viewpoints of teachers of different subjects within the STEM (Science, Mathematics, and Technology) disciplines which may contribute to their observation of these requirements, as well as spreading the culture of STEM education, and drawing teachers 'attention to it. It also provides an instrument for measuring STEM application requirements and teachers' attitudes toward STEM teaching. The study of teachers' attitudes towards STEM education also provides education program planners with what to focus on in preparation and qualification programs.

\section{Study Limits}

The study was limited to teachers of mathematics, science, and computer in public elementary and secondary schools in Ajloun Governorate in Jordan for the academic year 2019/2020. It was also limited to 
Table 1. Distribution of the study respondents and its sample according to the (gender, specialization, and stage of study) variables

\begin{tabular}{lcccccccc}
\hline \multirow{2}{*}{ The study respondents } & \multicolumn{2}{c}{ Gender } & \multicolumn{3}{c}{ Specialty } & \multicolumn{2}{c}{ Study stage } \\
\cline { 2 - 8 } & Male & Female & Science & Math. & Computer & Primary & Secondary & Total \\
\hline Study community & 279 & 357 & 280 & 271 & 85 & - & 636 \\
Study sample & 70 & 89 & 70 & 68 & 21 & 87 & 72 \\
\hline
\end{tabular}

defining four disciplines for the requirements of applying the STEM approach: changing education goals, changing teachers 'perceptions, changing teaching strategies, and requirements related to the school environment.

\section{Study Determinants}

These are determined by the psychometric properties of the scale of requirements for the application of the STEM approach, and the attitudes of teachers towards it which were prepared for the study, sample, and methodology used in the study.

\section{Study Terminology}

STEM: refers to adopting a multidisciplinary approach to education where scientific, mathematical, engineering and technological concepts are presented in an integrated manner with the natural phenomena in the classroom lessons in the way they appear in the real world. Thus, students apply science and mathematics with the support of technology and engineering design in the contexts that make communication between the curriculum, school, and society relevant and meaningful to students (Tsupros, Kohler, \& Hallinen, 2009, p. 18).

Requirements for applying the STEM approach: means the current study with the logically built basic practices and skills that contribute to achieving integration between science and mathematics and employing both engineering design and technology in their teaching, and is measured by the total degree that teachers obtain from the study sample on the first hub of the study instrument that was prepared specifically for this the purpose.

Attitude: It is the tendency for a supportive or opposing response towards persons, subjects, or events, and it is a hypothetical construction that is not directly noticeable, but it can be inferred through the positive and negative evaluations of the individuals as the attitude core (Corsini \& Ozaki, 1984, p. 99). It is "the tendency to accept or reject one of the types of behavior or practices" (Al-Mubarak, 2019, p. 6). The researcher defines the attitudes of teachers towards STEM teaching: as a set of ideas and opinions formed by science, mathematics and computer teachers about the STEM approach that directs their use of technology and engineering design in teaching mathematics and science, which is measured by the total degree that teachers obtain from the study sample on the second hub of the study instrument that has been specifically designed for this purpose.

\section{METHODOLOGY AND PROCEDURES}

\section{Study Methodology}

The present study used the descriptive- approach survey to reveal the requirements of the STEM approach and the attitudes of teachers towards it by analyzing the responses of the study sample individuals on the study scale.

\section{Study Sample Respondents}

The sample of the study consisted of 159 male and female teachers chosen by the stratified random method. And $25 \%$ of the study community consists of all teachers of science, mathematics, and computer (educational technology) in Ajloun Governorate and the total number was 636 teachers. The researcher chose his sample to be of multi- specialties to be in line with STEM approach. The teachers concerned with teaching these subjects in Jordan are teachers of mathematics, science and computer (education technology), and Table 1 shows the distribution of community members and sample study.

\section{Study Instrument}

The researcher has developed a scale that aims to determine the requirements of implementing the STEM approach and teachers' attitudes towards it, through the following steps:

Preparation of the preliminary form of the scale: The researcher has prepared a scale consisting of 50 phrases according to Likert -Fifth Scale that measures the indicators of the application of the STEM approach and attitudes towards it, distributed to two basic hubs; the first was to measure the requirements of the application of the STEM approach and had 30 statements measuring four sub-dimensions of the requirements of the application of the STEM approach, and the second hub consisted of 20 statements that measures the attitudes of male and female science and mathematics and computer(educational technology) teachers in the elementary and secondary stages about STEM. The scale was designed after reviewing the instruments of some studies (Al-bez, 2016; Al-O'taibi, 2018; EL-Deghaidy, et al, 2017; Maryland State Department of education, 2012).

Scale validity: The accuracy of the scale was confirmed by presenting it to referees and specialists in 
Table 2. Arithmetic means and standard deviations for teachers 'estimating degrees of STEM teaching requirements $(\mathrm{n}=159)$

\begin{tabular}{lccccc}
\hline STEM requirements & Item & Number & $\begin{array}{c}\text { Total } \\
\text { degree }\end{array}$ & Arithmetic mean & $\begin{array}{c}\text { Hypothetical mean } \\
* 75 \%\end{array}$ \\
\hline Changing learning goals & $1,2,3,4,5,6,7,8$ & 8 & 40 & 30.15 & 30 \\
Changing teachers' vision and skills & $9,10,11,12,13,14,15,16$ & 8 & 40 & 30.13 & 30 \\
Changing teaching methods & $17,18,18,19,20,21,22,23,24$ & 8 & 40 & 30.29 & 30 \\
Changing the classroom environment & $56,26,27,28,29,30$ & 6 & 30 & 22.37 & 22.5 \\
\hline Total degree & $1-30$ & 30 & 150 & 112.870 & 112.5 \\
\hline
\end{tabular}

the methods of teaching mathematics and science, measurement, and evaluation to know their views on the adequacy of the statements for the STEM concept and the scientific and linguistic validity of the scale phrases. And in the light of the referees' notes, the wording of some unclear items was modified.

Scale Stability: To verify the stability of the scale, it was applied to an exploratory sample of the study community and outside its primary samples to consist of 30 male and female teachers. Then, the scale was reapplied by a difference of two weeks, and the correlation coefficient between the responses of teachers in the two applications was calculated to calculate the stability factor by the way of repetition, reaching the coefficient of stability of the scale as a whole 0.82 , reaching the hub of STEM teaching requirements 0.80 , and "changing education goals" dimension was 0.78. "Changing teachers "perceptions and skills" domain got 0.86, "changing teaching methods" dimension had 0.90, and "requirements related to the classroom environment" was 0.78 . The hub of attitudes towards STEM was 0.90 .

\section{RESULTS AND DISCUSSION}

\section{Results related to the First Question: What are the Requirements for Applying the STEM Approach to Teaching in Jordan from of Science, Mathematics and Computer Teachers' Points of View?}

Table 2 shows that the arithmetic means of teachers' estimating degrees of STEM requirements are all high (more than 3.67) and above the hypothetical average (75\% of the total degree*). And the overall arithmetic mean of teachers' estimations for STEM teaching requirements (112.87) is higher than the estimated hypothetical mean (112.50). The domain of "changing teaching methods" was the highest average (30.29), followed by the domain of "changing learning goals" as the second place with an arithmetic mean (30.15). The third place was for "changing the teachers' vision and skills" with arithmetic mean (30.13). The last place was for "changing the classroom environment" with arithmetic mean (22.37). All of the former domains were higher than the hypothetical mean estimated by the current study of $75 \%$ of the total degree per dimension.

The previous result reflects the teachers' awareness of the requirements of applying STEM approach in Jordanian schools, attributing this result to the openness of teachers to modern trends in teaching, in addition to the widespread talk about STEM approach recently, and the application of many schools to this trend especially the private ones. This result can be based on teachers' awareness of STEM's overall goal of linking education to the daily life of the student and its contribution to the identification and guidance of learning outcomes to meet the need of the national economy. This result was consistent with the results of several previous studies, such as the (Al Basha, 2018) study which showed that teachers' beliefs towards the application of STEM were high, as well as the results of (Al-Enezi \& Algebr, 2017) study which found a higher level of teachers' perceptions related to STEM teaching requirements.

\section{Results related to the Second Question: What are the Science, Mathematics and Computer Teachers' Attitudes towards Teaching STEM Approach?}

The researcher used the following measures: Means more than 3.67 represents high attitude level; Means between 3.33 and 3.67 represent average attitude level; Means less than 3.33 represents low attitude level.

Table 3 shows the arithmetic means of teachers' attitudes towards STEM teaching, with a general arithmetic mean of teachers' attitudes (3.68). The standard deviation was 0.34 , a high attitude score. The teachers' attitudes towards STEM-oriented hub items ranged between 3.87 and 2.39 .

Previous results reflect high attitudes among science, mathematics and computer teachers towards STEM teaching, and the researcher explains this finding that STEM method employs technological practices and engineering design in the teaching of science and mathematics and an effort to address the innovated local and global problems. This has generated a conviction among teachers about the modernity and importance of teaching STEM. Besides, the Ministry of Education in Jordan is seeking to spread STEM culture in schools and promote it as the latest trends in science and mathematics teaching. This finding can also be attributed to the fact that STEM is based on teaching science and mathematics through their life applications in a realistic context, which improves students' attitudes towards studying these subjects, and their sense of the importance of science and mathematics in everyday life.

As for the phrases that got the average level of the attitudes are 1,13,19,16 as they tackled "teaching STEM difficulty", "helping students to connect STEM knowledge", "making students take the lead", and " STEM approach does not match with the students' levels 
Table 3. Arithmetic means of teachers' attitudes towards STEM ( $\mathrm{n}=159)$

\begin{tabular}{|c|c|c|c|c|}
\hline No. & Item & Means & Std.d. & level \\
\hline 6 & $\begin{array}{l}\text { STEM keeps pace with others in terms of mathematics, science, engineering and technology education } \\
\text { domains }\end{array}$ & 3.87 & 0.41 & high \\
\hline 4 & STEM teaching provides an educational suitable environment for science and mathematics & 3.86 & 0.42 & high \\
\hline 10 & $\begin{array}{l}\text { The STEM trend contributes to increasing the number of learners wishing to enroll in professional and } \\
\text { engineering specialization -study programs }\end{array}$ & 3.84 & 0.63 & high \\
\hline 17 & $\begin{array}{l}\text { I think scientific and mathematical concepts grow and form better if they comply with the STEM } \\
\text { integrative approach }\end{array}$ & 3.83 & 0.52 & high \\
\hline 11 & The STEM approach helps schools support school curricula and enrich science and mathematics lessons & 3.83 & 0.52 & high \\
\hline 2 & I think using the STEM trend deepens my understanding of the class subject & 3.82 & 0.62 & high \\
\hline 5 & $\begin{array}{l}\text { The STEM trend contributes to my learning of new subjects in mathematics, science and engineering } \\
\text { design. }\end{array}$ & 3.80 & 0.63 & high \\
\hline 9 & $\begin{array}{l}\text { The STEM approach provides learners with productive skills such as creative thinking, critical thinking, } \\
\text { and creative problem solving in real contexts. }\end{array}$ & 3.79 & 0.64 & high \\
\hline 3 & I believe STEM teaching leads to a deeper understanding of science, mathematics, and technology & 3.79 & 0.65 & high \\
\hline 18 & STEM teaching contributes to the search for multiple sources of knowledge & 3.79 & 0.67 & high \\
\hline 12 & I believe that STEM teaching is an appropriate method for using information technology & 3.79 & 0.67 & high \\
\hline 7 & The teacher guide does not support STEM-oriented application & 3.78 & 0.63 & high \\
\hline 8 & $\begin{array}{l}\text { The STEM trend contributes to transforming learners from mere recipients of knowledge and technology } \\
\text { into its producers }\end{array}$ & 3.77 & 0.58 & high \\
\hline 15 & STEM takes into account updating educational developments & 3.77 & 0.60 & high \\
\hline 20 & STEM teaching broadens the perceptions of learners to research natural phenomena and global problems & 3.73 & 0.55 & high \\
\hline 14 & $\begin{array}{l}\text { I see the need for students to use extra-curricular activities that integrate science, mathematics, } \\
\text { engineering, and technology }\end{array}$ & 3.73 & 0.55 & high \\
\hline 1 & $\begin{array}{l}\text { I find it difficult to implement STEM because it requires teaching activities within non-specialized } \\
\text { subjects }\end{array}$ & 3.60 & 0.87 & \\
\hline 13 & $\begin{array}{l}\text { The STEM approach makes it easy for learners to make meaningful real connections between science and } \\
\text { mathematics knowledge and skills, engineering design and technology }\end{array}$ & 3.39 & 0.74 & Medium \\
\hline 19 & $\begin{array}{l}\text { Teaching according to STEM makes learners follow the path of scientists in research and } \\
\text { experimentation }\end{array}$ & 3.38 & 0.75 & Medium \\
\hline 16 & STEM approach does not match with the students' levels in Jordan & 2.39 & 0.95 & Medium \\
\hline \multicolumn{2}{|r|}{ The domain of teachers' attitudes towards STEM as a whole } & 3.68 & 0.34 & high \\
\hline
\end{tabular}

in Jordan". This reflects that teachers and students can apply STEM orientation from teachers' points of view and with an average degree which, in turn, requires intensified efforts to train teachers and students, providing them with the appropriate skills to apply STEM orientation. And yet, this may be hindered by the difficulties of teachers in STEM application mechanisms or students' lack of readiness for this approach.

This finding is consistent with the results of some previous studies such as Ibrahim's and Al-Jaza'iri's study (2014), which showed that the trends of science teachers towards the integration of science and mathematics are high and (Gottfried, 2015) study showed that teaching STEM at an early stage improves students' attitudes to study their subjects in the future. (Al-Enezi \& Algebr, 2017) study $h$ found high perceptions among science teachers about STEM knowledge and teaching requirements, and (Al Basha, 2018) study showed positive attitudes among teachers towards STEM education. Shahali, Halim, Rasul, Osman and Zulkifeli (2018) study found positive attitudes among students towards learning STEM approach. Results related to the third question: Do the math, science and computer teachers' estimates of STEM application requirements and attitudes vary according to the gender, specialization, and study stage variables?
Table 4 showed that there are no statistically significant differences at the level 0.05 among male and female teachers' estimates of STEM application requirements along with their attitudes towards it according to the gender variable. Unlikely, there are statistically significant differences in their estimates according to the study phase variable to be in favor of the elementary stage. And there are statistically significant differences according to the specialty variable. And to find out in favor of any of the specialization categories these differences refer to, the Scheffe's test of dimensional comparisons was used.

Table 5 shows that the differences between teachers' assessments regarding each of the requirements of applying the STEM approach and the attitude towards STEM teaching were in favor of science and mathematics teachers compared to computer ones.

The researcher explains that there are no differences in the responses of the study sample respondents according to the gender variable, since the number of teachers at the university level is unified between males and females (mixed education). As well, the in-service training is unified in all regions of the Hashemite Kingdom of Jordan which made the awareness of male and female teachers to the requirements of applying the STEM approach and the attitude towards it approximate. This result is consistent with Berlin and 
Table 4. The Multi-variability analysis test to indicate differences in sample responses according to (gender, stage, and specialization) variables. $(\mathrm{n}=159)$

\begin{tabular}{|c|c|c|c|c|c|c|}
\hline Dependent variable & $\begin{array}{l}\text { Independent } \\
\text { variable }\end{array}$ & Category & No. & Means & Std.d. & Test \\
\hline STEM Teaching & Gender & Female & 89 & 3.76 & .25 & Multiple variance analysis \\
\hline \multirow[t]{6}{*}{ Requirements } & & Male & 70 & 3.77 & .14 & $\mathrm{~F}=1.59$ Significance $=.209$ \\
\hline & Specialty & Science & 70 & 3.80 & .10 & Multiple variance analysis \\
\hline & & Mathematics & 68 & 3.79 & .13 & $\mathrm{~F}=21.42$ Significance $=.000$ \\
\hline & & Computer & 21 & 3.54 & .44 & \\
\hline & & Elementary Stage & 87 & 3.81 & .09 & Multiple variance analysis \\
\hline & Study Stage & Secondary Stage & 72 & 3.71 & .28 & $\mathrm{~F}=19.60$ significance $=.000$ \\
\hline Attitude towards & Gender & Female & 89 & 3.67 & .42 & Multiple variance analysis \\
\hline \multirow[t]{6}{*}{ STEM Teaching } & & Male & 70 & 3.69 & .21 & $\mathrm{~F}=1.60$ to signify $=0.212$ \\
\hline & Specialty & Science & 70 & 3.76 & .16 & Multiple variance analysis \\
\hline & & Mathematics & 68 & 3.71 & .19 & $\mathrm{~F}=23.48$ Significance $=.000$ \\
\hline & & Computer & 21 & 3.30 & .72 & \\
\hline & & Elementary Stage & 87 & 3.74 & .15 & Multiple variance analysis \\
\hline & Study Stage & Secondary Stage & 72 & 3.60 & .47 & $\mathrm{~F}=15.80$ Significance $=.000$ \\
\hline
\end{tabular}

Table 5. Scheffe's results according to the specialty variable. $(n=159)$

\begin{tabular}{lccccc}
\hline Dependent variable & Specialty & means & Science & Mathematics & Computer \\
\hline STEM Teaching Requirements & Science & 3.80 & - & 0.0091 & - \\
& Mathematics & 3.79 & - & - & $0.2609\left(^{*}\right)$ \\
& Computer & 3.54 & - & - & $0.2518\left(^{*}\right)$ \\
\hline Attitude towards & Science & 3.76 & - & 0.0519 & $0.4607\left({ }^{*}\right)$ \\
STEM Teaching & Mathematics & 3.71 & - & - & $0.4088\left(^{*}\right)$ \\
& Computer & 3.30 & - & - & - \\
\hline
\end{tabular}

White (2011), Ibrahim and Aljazaeri (2014), AL Basha (2018) and Al-Enezi and Algebr (2017) that showed no statistically significant differences in teachers' perceptions towards integration between Science, mathematics, engineering, and technology by gender variable.

The researcher explains the presence of differences in teachers' responses to the variable of the school stage to go for the benefit of the elementary stage K-10 because of the mechanism of preparing science teachers in colleges of educational sciences concerned with teaching the elementary stage, especially K-7 grades. The teachers are prepared to teach science within one book including Physics, biology, and geology. Besides, the Ministry of Education trains newly appointed teachers to teach all subjects of the elementary stage. Moreover, the Ministry of Education has an interest in the application of STEM in the elementary- stage classes to develop the competencies of learners as well as providing the needed requirements for applying such an approach. While the secondary stage in Jordan contains only two grades, the first secondary and the second secondary. The high school test Tawjihi Exam poses a high risk which makes secondary-stage teachers focus on preparing students for the high school test and makes them move away from modern trends in teaching so that they do not raise the level of anxiety among students. This result is consistent with Al-E'nezi and Algebr (2017) that showed that there were no statistically significant differences in teachers' perceptions towards STEM according to the study stage variable and in favor of the elementary stage compared to the secondary one. It differed with Al Basha (2018) that showed the differences are in favor of the intermediate stage compared to the elementary one.

The researcher explains the existence of differences in the responses of the study members according to the specialization variable and for the benefit of science and mathematics teachers compared to computer ones to the nature of science curricula in the elementary stage. Physics, chemistry, biology, and geology are taught with a single curriculum science book. Thus, science teachers are prepared to teach this stage so that they can teach any discipline within the science disciplines regardless of the teacher's specific specialization. The mathematics curriculum includes many problems related to science disciplines, and the science curriculum includes applications for mathematics which make mathematics and science teachers are more experienced in STEMs and activities than computer and educational technology ones who only teach computer subject and are merely far away from other subjects. This current study is the first within the limits of the researcher's knowledge that examined the differences between the estimates of science and mathematics and computers teachers towards applying STEM approach requirements and their attitudes.

\section{CONCLUSION}

This study is considered one of the first studies related to the field of integration requirements between science, engineering, technology and mathematics in Jordan. Accordingly, it seeks to reveal the requirements of applying the STEM approach in Jordan, and the teachers' attitudes about STEM teaching, at various 
academic levels and from the viewpoint of teachers of different subjects within the STEM disciplines, Science, Mathematics, and Technology, which may contribute to their observation of these requirements. This study contributes to spreading the culture of STEM education. And at the end of this study, the researcher concluded that the attitudes of science, mathematics and computer technology teachers are high towards STEM. And that teachers agree to the requirements of applying the STEM approach in Jordan mentioned in the study instrument and to a high degree. This approval came primarily from the viewpoint of the teachers participating in studying the requirements related to changing teaching methods. Changing the learning goals dimension followed secondly, and then followed by the domain of changing teachers 'vision and skills related to STEM. changing the classroom environment domain came last. It was found that the opinions of teachers of both genders are close to the requirements of STEM implementation and the approach towards it, while there are statistically significant differences in their estimates according to the study stage variable and in favor of the elementary stage. There are statistically significant differences according to the variable of specialization and for the benefit of science and mathematics teachers compared to computer ones.

\section{Recommendations}

In light of the results of the current study, the following recommendations can be made:

1. The need to provide all the requirements for applying the STEM Approach which is highly approved by the sample- study respondents, as shown in the study results.

2. Increasing the awareness of computer teachers about the requirements of applying STEM and their supporting role in science and mathematics education, the study showed that they are the least familiar with the requirements of applying STEM Approach.

3. Investing the positive attitudes of teachers about STEM teaching in developing teachers' performance to employ engineering design and technology in the implementation of science and mathematics activities.

4. The researcher recommends a study surveying students' learning when applying STEM in math and science classes.

\section{REFERENCES}

Al Basha, H. (2018). Investigating Teachers' Perceptions and Implementation of STEM Education in the United Arab Emirates (Master Thesis). United Arab Emirates: The British University in Dubai Faculty of Education. Retrieved from https://bspace.buid.ac. ae/bitstream/1234/1163/1/2015101115.pdf
Al-bez, D. (2016). Analysis of the Content of Science Textbooks in the Upper Grades of Primary School in the Light of the Requirements of STEM. Journal of the world of education, ASCHRD, 8(2), 1-69. Retrieved from https://platform.almanhal.com/Files/2/ 108862

Al-Enezi, A., \& Algebr, J. (2017). Investigate the Level of Science Teachers in Saudi Arabia Perception about STEM Approach and its Relation to Some Variables. Journal of the Faculty of Education, 33(2), 613-647. Retrieved from https://platform. almanhal.com/Files/2/110588

Al-Mubarak, H. (2019). Trends of the Faculty Members at AL-Imam Al-Mahdi University, the Colleges of Education and Nursing, in Using the Modern Means of Teaching. The Arab Journal of Educational and Psychological Sciences, 7, 1-24. Retrieved from http: / / search.shamaa.org/FullRecord?ID=24179

Al-O'taibi, A. (2018). The Perceptions of Teachers of Elementary, Middle and Secondary Education towards Learning through the STEM Entrance in Afif Governorate. Basic Education College Magazine for Educational and Humanities Sciences, 41, 1-24. Retrieved from https://www.iasj.net/iasj?func= article\&aId=153795

Alqadhi, A., \& Rabia, S. (2018). Guide to Effective Practice of STEM and STEAM. Bahrain: Dar Al-Elhekma for Publishing and Distribution.

Berlin, D., \& Kyungpook, H. (2005). Integrating Science and Mathematics Education: Historical Analysis. School Science and Math., 105(5), 15-24. https:/ / doi. org/10.1111/j.1949-8594.2005.tb18032.x

Berlin, D., \& White, A. (2011). A Longitudinal Look at Attitudes and Perceptions Related to the Integration of Mathematics, Science, and Technology, Education. School Science and Mathematics, 112(1), 20-30. https://doi.org/ 10.1111/j.1949-8594.2011.00111.x

Bybee, R. (2013). The case for STEM education: Challenges and opportunities. Arlington, Virginia: National Science Teachers Association Press.

Corsini, R., \& Ozaki, B. (1984). Encyclopedia of Psychology. New Jersey: John Wiley and Sons.

Reeve, E. (2015). STEM Thinking. Technology and Engineering Teacher, 75(4), 8-16. Retrieved from https:/ / eric.ed.gov/ ?id=EJ1047255

El-Deghaidy, H., Mansour, M., Alzaghibi, M., \& Alhammad, K. (2017). Context of STEM Integration in Schools: Views from in Service Science Teachers. EURASIA Journal of Mathematics Science and Technology Education, 13(6), 2459-2484. https://doi.org/10.12973/eurasia.2017.01235a

Eisenhart, M., Weis, L., Allen, C., Cipollone, K., Stich, A., \& Dominguez, R. (2015). High School Opportunities for STEM: Comparing iInclusive 
STEM Focused and Comprehensive High Schools in Two US Cities. Journal of Research in Science Teaching, 52(6), 763-789. https://doi.org/10.1002/ tea. 21213

Furner, J., Doan-Holbein, M., \& Scullion-Jackson, K. (2000). Taking an Internet Field Trip: Promoting Cultural and Historical Diversity through Mayan Mathematics. Tech Trends, 44(6), 18-22. https:// doi.org/10.1007/BF02763311

Gottfried, M. (2015). The Influence of Applied STEM Course Taking on Advanced Mathematics and Science Course Akin. The Journal of Educational Research, 108(5), 382-399. https:/ / doi.org/10.1080/ 00220671.2014.899959

Gonzalez, H., \& Kuenzi, J. (2012). Science, Technology, Engineering, and Mathematics STEM education: A primer. USA: Prepared for Members and Committees of Congress Congressional. Retrieved from https:/ /fas.org/sgp/crs/misc/R42642.pdf

Ibrahim, H., \& Aljazaeri, K. (2014). Classroom Beliefs about the Integration of Mathematics and Science in the First Cycle of Basic Education in Southern Syria. Journal of the Federation of Arab Universities for Education and Psychology, 12(3), 11-31. Retrieved from http://search.shamaa.org/PDF/Articles/ SYAaujep/AaujepVol12No3Y2014/aaujep_2014v12_n3_011-031.pdf

Kelly, T., \& Knowles. J. (2016). A Conceptual Framework for Integrated STEM Education. International Journal of STEM Education, 3(1), 1-11. https:/ / doi.org/10.1186/s40594-016-0046-Z

Maryland State Department of Education. (2012). Maryland State STEM Standards of Maryland. Washington, DC: The National Academies Press. https://cutt.us/jkSpT

Ministry of Finance. (2019). Government Finance Bulletin, Studies \& Economic Policies Directorate, 12(8), 1-75. Retrieved from https://www.imf.org/ en/Countries/JOR

National Research Council (NRC). (2011). Successful K-12 STEM Education: A workshop Summary. Washington, DC: The National Academies Press. https://cutt.us/it8Ke

National Research Council (NRC). (2012). A Framework for K-12 Science Education: Practices, Crosscutting Concepts, and Core Ideas. Committee on a conceptual framework for New K-12 science education standards. Board on Science Education, Division of Behavioral and Social Sciences and Education. Washington, DC: The National Academies Press. Retrieved from https://www.nap.edu/read/ 13165/chapter/1
O'Connell, K., Keys, B., \& Storksdieck, M. (2017). Taking Stock of Oregon STEM Hubs: Accomplishments and Challenges An Evaluation, Report Prepared for the Oregon Chief Education Office. https:// doi.org/10.5399/osu/1121

Popovic, G., \& Lederman, J. (2015). Implications of Informal Education Experiences for Mathematics Teachers' Aability to Make Connections beyond the Formal Classroom. School Science and Mathematics, 115(3), 129-140. https://doi.org/10.1111/ssm. 12114

Shahali, E., Halim, L., Rasul, M., Osman, K., \& Zulkifeli, M. (2018). STEM Learning through Engineering Design: Impact on Middle Secondary Students' Interest towards STEM. EURASIA Journal of Mathematics Science and Technology Education, 13(5), 1189-1211. https:/ / doi.org/10.12973/eurasia.2017. 00667a

Seyranian,V., Madva, A., Duong, N., Abramzon, N., Tibbetts, Y., \& Harackiewic, J. (2018). The Longitudinal Effects of STEM Identity and Gender on Flourishing and Achievement in College Physic, International Journal of STEM Education, 5(40), 1-14. https:// doi.org/10.1186/s40594-018-0137-0

Stephanie, P. M. (2008). Blessed Unrest: The Power of Unreasonable People to Change the World. NCSSSMST Journal. National Consortium for Specialized Secondary Schools of Mathematics. Science and Technology. NCSSSMST Professional Conference, 13(2), 8-14. Retrieved from https:/ / www.stephanie pacemarshall.com/articles/SPM-Article10-BlesUn rest.pdf

Tarman, B. (2012). Prospective Teachers' Beliefs and Perceptions about Teaching as a Profession. Educational Sciences: Theory and Practice, 12(3), 1-24. Retrieved from https:/ / eric.ed.gov/ ?id=EJ1000904

TIMSS. (2015). About TIMSS 2015, International Study Center Lynch School of Education, Boston College. Retrieved from http:/ / timssandpirls.bc.edu/timss 2015/international-results/wp-content/uploads/ filebase/full\%20pdfs/T15-International-Resultsin-Mathematics.pdf

Tsupros, N., Kohler,R. \& Hallinen,J. ( 2009). STEM Education: A Project to Identify the Missing Components, Intermediate Unit 1 and Carnegie Mellon, Pennsylvania.

Warsi, S. (2019). Importance of STEM Education In The Indian Education EcosySTEM. Franchise India Education journal. Retrieved from https://www. franchiseindia.com/education/importance-ofSTEM-education-in-the-indian-educationecosySTEM.13029 


\section{APPENDIX 1}

The scale of applying STEM Approach requirements and teachers' attitudes towards it

This questionnaire investigates Requirements for applying the STEM Approach and teachers' attitudes towards it. The information is used for academic research only and confidentiality is guaranteed. So kindly, answer all questions.

\section{Teachers' Data}
- Gender:
$\square$ Female
$\square$ Male
- Specialty:
$\square$ Science
$\square$ Math
$\square$ Computer (ICT)
-Study stage the teachers teach:
$\square$ Elementary
$\square$ Secondary

STEM Application Requirements in Jordanian Schools

\begin{tabular}{|c|c|c|c|c|c|c|}
\hline \multirow[t]{2}{*}{ No. } & \multirow[t]{2}{*}{ Requirements } & \multicolumn{5}{|c|}{ Response } \\
\hline & & SA & A & $\mathbf{N}$ & D & SD \\
\hline \multicolumn{7}{|c|}{ Requirements related to changing learning goals and content } \\
\hline 1 & Focus on the concept of integrated expertise & & & & & \\
\hline 2 & $\begin{array}{l}\text { Researching issues in the surrounding environment or the world, and providing } \\
\text { solutions to them in the context of my life }\end{array}$ & & & & & \\
\hline 3 & The use of engineering design in science and mathematics practices & & & & & \\
\hline 4 & $\begin{array}{l}\text { Achieving an understanding of science, mathematics, and their technical applications by } \\
\text { all students }\end{array}$ & & & & & \\
\hline 5 & Depending on multiple sources of knowledge, especially digital & & & & & \\
\hline 6 & Design selected units according to the STEM trend and circulate them to schools & & & & & \\
\hline 7 & $\begin{array}{l}\text { The necessity to include the curriculum on activities that achieve engaging inquiry and } \\
\text { imagination. }\end{array}$ & & & & & \\
\hline 8 & Analyzing technology risks, limitations, and impacts & & & & & \\
\hline \multicolumn{7}{|c|}{ Requirements related to teachers' perceptions and skills } \\
\hline 9 & $\begin{array}{l}\text { Ability to plan and implement integration activities between science, engineering, } \\
\text { mathematics, and technology topics }\end{array}$ & & & & & \\
\hline 10 & The desire to teach topics common to multiple STEM topics & & & & & \\
\hline 11 & Possessing the development of effective communication skills & & & & & \\
\hline 12 & Possessing the teaching strategies required by the STEM approach & & & & & \\
\hline 13 & The use of solid scientific language to express scientific topics and issues. & & & & & \\
\hline 14 & Possessing technological literacy skills & & & & & \\
\hline 15 & Familiarity with the STEM approach & & & & & \\
\hline 16 & The ability to coordinate teachers of other subjects within STEM journals & & & & & \\
\hline \multicolumn{7}{|c|}{ Requirements related to teaching strategies } \\
\hline 17 & Teaching mathematics through its life applications & & & & & \\
\hline 18 & Use search and survey strategies & & & & & \\
\hline 19 & Using critical thinking methods & & & & & \\
\hline 20 & Using technology strategically & & & & & \\
\hline 21 & $\begin{array}{l}\text { Supporting scientific content with positions that confirm the integration between two or } \\
\text { more STEM topics }\end{array}$ & & & & & \\
\hline 22 & $\begin{array}{l}\text { Using the strategy of patient questions that helps in answering the issues raised in the } \\
\text { book's content (local, international) }\end{array}$ & & & & & \\
\hline 23 & Motivating learners to use methods of debate and scientific lecture & & & & & \\
\hline 24 & Use collaborative learning strategies and motivate students to share ideas with the team & & & & & \\
\hline \multicolumn{7}{|c|}{ Requirements related to the school environment } \\
\hline 25 & $\begin{array}{l}\text { Providing the necessary equipment and techniques to implement integration activities } \\
\text { between science, mathematics, and technology }\end{array}$ & & & & & \\
\hline 26 & Provide an engineering design operator or science lab support for this & & & & & \\
\hline 27 & Make the science lab available for math lessons & & & & & \\
\hline 28 & Connecting schools to the Internet and making them available to all students & & & & & \\
\hline 29 & Providing an encouraging and interesting class environment for students & & & & & \\
\hline 30 & The school leadership is convinced of the importance of STEM Approach & & & & & \\
\hline
\end{tabular}

(SA) Strongly Agree; (A) Agree; (N) Neutral; (D) Disagree; (SD) Strongly Disagree 


\section{Attitudes towards STEM Teaching}

\begin{tabular}{|c|c|c|c|c|c|c|}
\hline \multirow[t]{2}{*}{ No. } & \multirow[t]{2}{*}{ Item } & \multicolumn{5}{|c|}{ Response } \\
\hline & & SA & $\mathbf{A}$ & $\mathbf{N}$ & $\mathbf{D}$ & SD \\
\hline 1 & $\begin{array}{l}\text { I find it difficult to implement STEM because it requires teaching activities within non- } \\
\text { specialized subjects }\end{array}$ & & & & & \\
\hline 2 & I think using the STEM trend deepens my understanding of the class subject & & & & & \\
\hline 3 & $\begin{array}{l}\text { I believe STEM teaching leads to a deeper understanding of science, mathematics, and } \\
\text { technology }\end{array}$ & & & & & \\
\hline 4 & $\begin{array}{l}\text { STEM teaching provides an educational suitable environment for science and } \\
\text { mathematics }\end{array}$ & & & & & \\
\hline 5 & $\begin{array}{l}\text { The STEM trend contributes to my learning of new subjects in mathematics, science and } \\
\text { engineering design. }\end{array}$ & & & & & \\
\hline 6 & $\begin{array}{l}\text { STEM keeps pace with others in terms of mathematics, science, engineering and } \\
\text { technology education domains }\end{array}$ & & & & & \\
\hline 7 & The teacher guide does not support STEM-oriented application & & & & & \\
\hline 8 & $\begin{array}{l}\text { The STEM trend contributes to transforming learners from mere recipients of knowledge } \\
\text { and technology into its producers }\end{array}$ & & & & & \\
\hline 9 & $\begin{array}{l}\text { The STEM approach provides learners with productive skills such as creative thinking, } \\
\text { critical thinking, and creative problem solving in real contexts. }\end{array}$ & & & & & \\
\hline 10 & $\begin{array}{l}\text { The STEM trend contributes to increasing the number of learners wishing to enroll in } \\
\text { professional and engineering specialization -study programs }\end{array}$ & & & & & \\
\hline 11 & $\begin{array}{l}\text { The STEM approach helps schools support school curricula and enrich science and } \\
\text { mathematics lessons }\end{array}$ & & & & & \\
\hline 12 & I believe that STEM teaching is an appropriate method for using information technology & & & & & \\
\hline 13 & $\begin{array}{l}\text { The STEM approach makes it easy for learners to make meaningful real connections } \\
\text { between science and mathematics knowledge and skills, engineering design and } \\
\text { technology }\end{array}$ & & & & & \\
\hline 14 & $\begin{array}{l}\text { I see the need for students to use extra-curricular activities that integrate science, } \\
\text { mathematics, engineering, and technology }\end{array}$ & & & & & \\
\hline 15 & STEM takes into account updating educational developments & & & & & \\
\hline 16 & STEM approach does not match with the students' levels in Jordan & & & & & \\
\hline 17 & $\begin{array}{l}\text { I think scientific and mathematical concepts grow and form better if they comply with the } \\
\text { STEM integrative approach }\end{array}$ & & & & & \\
\hline 18 & STEM teaching contributes to the search for multiple sources of knowledge & & & & & \\
\hline 19 & $\begin{array}{l}\text { Teaching according to STEM makes learners follow the path of scientists in research and } \\
\text { experimentation }\end{array}$ & & & & & \\
\hline 20 & $\begin{array}{l}\text { STEM teaching broadens the perceptions of learners to research natural phenomena and } \\
\text { global problems }\end{array}$ & & & & & \\
\hline
\end{tabular}

(SA) Strongly Agree; (A) Agree; (N) Neutral; (D) Disagree; (SD) Strongly Disagree

\section{http://www.ejmste.com}

